\title{
Awareness of Physicians in Yemen Toward High Blood Pressure Management According to the Eighth Joint National Committee (JNC 8) Guideline
}

This article was published in the following Dove Press journal:

International Journal of General Medicine

\author{
Abdulsalam M Halboup $\mathbb{D}^{1}$ \\ Gamil Q Othman' \\ Mohammed M Battah (D) \\ Karem H Alzoubi $\mathbb{1 D}^{2}$ \\ Hebah Sallom ${ }^{3}$ \\ 'Departments of Clinical Pharmacy and \\ Pharmacy Practice, Faculty of Pharmacy, \\ University of Science and Technology, \\ Sana'a, Yemen; ${ }^{2}$ Department of Clinical \\ Pharmacy, Faculty of Pharmacy, Jordan \\ University of Science and Technology, \\ Irbid, Jordan; ${ }^{3}$ Department of Clinical \\ Pharmacy, Faculty of Pharmacy, Near East \\ University, Nicosia, Cyprus, Turkey
}

Background: Hypertension is a common public health problem that impacts more than onethird of the world population. Awareness of physicians towards the guidelines of high blood pressure management is an essential step to reduce the consequences of high blood pressure. Objective: This study was aimed to assess the awareness of physicians towards high blood pressure treatment according to the recent report of the Joint National Committee (JNC8) guideline.

Methods: A self-administered questionnaire was distributed to 400 physicians during the period from February to April 2017. Physicians were recruited from public and private hospitals as well as clinics. A validated questionnaire that incorporated the changes seen in JNC 8, as well as the specific modality of hypertension management based on other guidelines, was administered to the participating physicians.

Results: Three hundred and eighty-nine physicians completed the questionnaire; with all the interviewed physicians have ever heard about JNC 8 . The practice of general practitioners (GPs) was significantly deviated from the recommended guideline of blood pressure management as compared to consultants, specialists, and residents. Additionally, certain variations were found among consultants, specialists, and residents with slight superiority of consultants towards most aspects.

Conclusion: The finding of this study highlights an inadequate knowledge of GPs in Yemen towards high blood pressure management guidelines. The findings of this study emphasize the necessity for continuous medical education programs that are specially designed to target GPs. Continued update of medical curricula in Yemeni universities is also needed.

Keywords: hypertension, practitioners, physicians, guidelines, Yemen

\section{Introduction}

Hypertension is a common public-health challenge worldwide. By 2025, it is estimated that over 1.56 Billion of the world population will have hypertension. ${ }^{1}$ Long-standing hypertension is considered a major risk factor for coronary artery disease, stroke, heart failure, peripheral vascular disease, vision loss, and chronic kidney disease. $^{2-5}$ The Joint National Committee (JNC) on Prevention, Detection, Evaluation, and Treatment of High Blood Pressure issues hypertension-related guidelines after reviewing emerging therapies and outcomes of ongoing clinical trials. The JNC 8 was the latest guideline released in 2014. It includes major
Correspondence: Mohammed M Battah Tel +967-777404880

Email mmalbattah@gmail.com 
differences from the previous reports regarding the threshold of starting antihypertensive medications, the therapeutic goal of blood pressure (JNC 8 defined similar therapeutic goals for the majority of hypertensive patients except elderly), and the first line drugs category. In JNC 8, the first line drug can be equally selected from four specific classes rather than five classes in previous versions of the guideline. As per JNC 8, $\beta$-blockers were not recommended as first line therapy for patients without compelling indication. Additionally, one major difference is that the evidence of JNC 8 was limited to a systematic review of randomized clinical trials. ${ }^{6}$ However, several other points about hypertension were not addressed in the JNC 8 including the definition of hypertension, the use of standard medications in a hypertensive patient with heart failure, and the potential benefits of lifestyle changes. Therefore, these issues were incorporated from the guidelines of JNC 7, the American College of Cardiology Foundation/American Heart Association (ACCF/AHA), the lifestyle workgroup, and the American College of Obstetrician and Gynecologist. ${ }^{7-10}$

The JNC reports have served as a valuable source for making a clinical decision. The recommended guidelines help in decreasing the variations between practitioners and improving the quality of health care. ${ }^{11}$ Many studies have connected poor control of blood pressure with inadequate adherence to hypertension guidelines. ${ }^{12,13}$ Implementation of hypertension guidelines in a community with a high prevalence of hypertension might help in reducing untreated/inappropriately treated patients and later might help in reducing the long-term consequences associated with high blood pressure.

In Yemen, the estimated prevalence of hypertension for the age group between 30 and 64 is $17.1 \%$ and the crude prevalence was $13.5 \% .{ }^{14}$ Moreover, among elderly patients who were seeking cataract surgery in eye camps, hypertension was found to be the most prevalent systemic disease. ${ }^{15}$ However, no study has been conducted to evaluate the quality of the provided healthcare recommendations for the management of hypertension in Yemen. Hence, this study was aimed to assess the awareness of Yemeni physicians towards hypertension definition, diagnosis, and choice of reasonable therapeutics modalities. This study is also aimed to reveal the knowledge and practice of high blood pressure management among Yemeni physicians with different specialties.

\section{Materials and Methods}

\section{Study Design}

A self-administered questionnaire was used (appendix). The final questionnaire was developed in English language, and it consisted of two parts, the first part included four questions related to the demographic data of the participants, including age, gender, physician's category/ rank, and type of professional practice setting where they work. The second part included 17 questions, incorporated from JNC 8, JNC 7, ACCF/AHA, American College of Obstetrician and Gynecologist, and the lifestyle workgroup in order to have a comprehensive view about the management of hypertension. Each question has only one correct answer. The questionnaire consisted of 17 items. Five items dealt with classification and goal of therapy, another five items dealt with hypertension with compelling indications, four more items dealt with the lifestyle modifications, one question about pregnancy hypertension, one question about the combined use of Angiotensin Converting Enzyme Inhibitors (ACEi) along with Angiotensin Receptor Blockers (ARBs), and one question about the use of $\beta$-blockers in a hypertensive patient without compelling indications.

\section{Validation}

The questionnaire has been distributed among four academics with expertise in community medicine, clinical pharmacy, pharmacy practice, and pharmacology, and two internal medicine consultants. This is to ensure the accuracy, appropriateness, and relevance of the included items. The final questionnaire was designed as multiplechoice and the correct answer was one of three options; namely, agree, disagree, or I do not know. In order to ensure reliability and consistency of the questions, questionnaires were distributed among 30 physicians that were not included in the study sample. The calculated Cronbach's alpha was found to be 0.651 .

\section{Location and Time of the Study}

This study was conducted in Sana'a, the capital of Yemen. The study included 389 physicians; who were interviewed in three public hospitals, two military hospitals, thirty-two private hospitals, and seven clinics. These institutions were chosen to be representative of all hospitals in Yemen since these institutions serve as the referral hospitals for most of the patients in Yemen. The questionnaires were administered and collected within a three-month period from February to 
April 2017. The interviewed physicians took an average of 10 minutes to fill the questionnaire.

The study included all physicians who dealt with hypertension patients during their practice, such as general practitioners, cardiologists, nephrologists, gynecologists, and internal medicine physicians.

\section{Sample Size Calculation}

The last annual health statistics report that was published in 2014 reported the total number of physicians in Sana'a was 1732 physicians. Of them, 1081 were general prescribers and 651 were specialized physicians. ${ }^{16}$ OpenEpi website (http://www.openepi.com/Menu/OE Menu.htm) was used for the sample size calculation. Participants $(n=315)$ were determined as representative samples with $95 \%$ confidence level and 5\% accuracy. With expected non-response rate of $20 \%$, the final sample size was approximately 380 .

\section{Data Collection}

The questionnaire was handed to physicians after explaining the purpose of the study to them. Five students in the fifth year of their pharmacy course at university of Science and Technology were trained on the study protocol before collecting data. Physicians were asked to complete the questionnaire and handed it back immediately after responding to the questions. Those physicians were divided into four groups: general practitioners (those who finished bachelor of medicine without doing specialty in any medical field), residents (those who have enrolled in four or-fiveyear residency program), specialists (those who have finished internal medicine residency), and consultants (those who have a subspecialty in a specific medical field, such as cardiologists or five-year elapsed after being specialist). ${ }^{17}$ The data obtained was checked and prepared for entry into statistical software for subsequent data analysis.

\section{Data Analysis}

All data were analyzed using IBM SPSS Statistics version 21.0 for Windows ${ }^{\circledR}$ (IBM Corp., Armonk, NY, USA). Descriptive statistics were used to express the demographic data of the participants. Chi-squared test was used to express the association between the participants' specialties and the questions. $P<0.05$ was considered statistically significant.

\section{Results}

\section{Demographic Data}

The questionnaire was completed by 389 physicians; thus, the response rate of the study was $97 \%$. The demographic characteristics of the participants are shown in Table 1. The participants of the study were mainly specialists $(38 \%$, $\mathrm{n}=146)$ followed by GPs $(23 \%, \mathrm{n}=91)$, residents $(20 \%$, $\mathrm{n}=79)$, and consultants $(19 \%, \mathrm{n}=73)$. Participants were mainly working in public hospitals $(44.73 \%, \mathrm{n}=174)$ followed by private hospitals $(35.73 \%, \mathrm{n}=139)$, and private clinics $(19.54 \%, \mathrm{n}=76)$. Participants were mostly male physicians $(71 \%, \mathrm{n}=276)$, and the age of the majority $(36 \%$, $\mathrm{n}=140$ ) was more than 40 years (Table 1). All participants reported that they have ever heard about JNC 8.

\section{Lifestyle Modifications}

The majority $(86 \%, \mathrm{n}=336)$ of participants agreed that DASH eating plan is recommended as a part of lifestyle changes for hypertension. Moderate physical exercise, reduction in sodium consumption, and weight loss were also recommended by $93.5 \%, n=364 ; 69.75 \%, n=270$; $96.75 \%, n=376$ of physicians, respectively (Table 2 ).

\section{Hypertension Classification and Goal of Therapy}

The majority of the participants $(78.7 \%, \mathrm{n}=306)$ knew the correct definition of the prehypertension. The majority also $78.9 \%(\mathrm{n}=307)$ agreed that blood pressure higher than

Table I Demographics of Physicians Involved in the Study $(n=389)$

\begin{tabular}{|l|l|l|l|}
\hline \multicolumn{2}{|l|}{ Characteristics } & Frequency & $\begin{array}{l}\text { Percent } \\
\text { (\%) }\end{array}$ \\
\hline Age (Years) & $\begin{array}{l}\text { Under } 30 \\
\text { From } 30 \text { to } 40\end{array}$ & 111 & $29 \%$ \\
& Above 40 & 140 & $35 \%$ \\
\hline \multirow{2}{*}{ Gender } & Male & 276 & $71 \%$ \\
\hline Physician category & Female & 113 & $29 \%$ \\
& Consultant & 73 & $19 \%$ \\
& Specialist & 146 & $38 \%$ \\
& Resident & 79 & $20 \%$ \\
& GPs & 91 & $23 \%$ \\
\hline Professional & Public hospital & 174 & $44.73 \%$ \\
practice & Private & 139 & $35.73 \%$ \\
& hospital & & \\
& Private clinic & 76 & $19.54 \%$ \\
\hline
\end{tabular}

Abbreviation: GPs, general practitioners. 
Table 2 Correct Answers Regarding Life Style Modifications ( $n=389)$

\begin{tabular}{|c|c|c|c|c|c|c|c|c|c|c|c|}
\hline \multirow[t]{2}{*}{ Lifestyle Modifications } & \multicolumn{2}{|c|}{ Consultant } & \multicolumn{2}{|c|}{ Specialist } & \multicolumn{2}{|c|}{ Resident } & \multicolumn{2}{|l|}{ GPs } & \multirow[t]{2}{*}{ Total } & \multirow[t]{2}{*}{ Chi-Square } & \multirow[t]{2}{*}{ P-value } \\
\hline & Freq. & $\%$ & Freq. & $\%$ & Freq. & $\%$ & Freq. & $\%$ & & & \\
\hline DASH & 65 & 89 & $|3|$ & 90 & 68 & 86 & 72 & 79 & $86 \%$ & 10.369 & 0.110 \\
\hline \multirow[t]{2}{*}{ Moderate exercise } & 70 & 96 & 140 & 96 & 75 & 95 & 79 & 87 & $93.5 \%$ & 12.858 & $0.045^{*}$ \\
\hline & 58 & 79 & 102 & 70 & 54 & 68 & 56 & 62 & $69.75 \%$ & 25.993 & $0.000^{*}$ \\
\hline Reduce sodium intake & & & & & 78 & & & & & & \\
\hline Weight loss & 72 & 99 & 142 & 97 & & 99 & 84 & 92 & $96.75 \%$ & $|0.32|$ & 0.112 \\
\hline
\end{tabular}

Note: *Significant $(\mathrm{P}<0.05)$.

Abbreviations: DASH, dietary approaches to stop hypertension; GPs, general practitioners.

$160 / 100 \mathrm{mmHg}$ is classified as stage 2 hypertension. Yet, only $64 \%(n=249)$ of physicians agreed that lowering blood pressure in patients aged 60 years or older without compelling indication to a level of less than $150 / 90 \mathrm{~mm}$ $\mathrm{Hg}$ is the target of their treatment. Moreover, 52.25\% $(n=205)$ of the physicians agreed that stage two hypertensive patients need antihypertensive drugs combination if the target cannot be achieved by a single drug (Table 3).

\section{Hypertension with Compelling Indications}

According to JNC 8, specific medication classes were recommended based on compelling indications, such as chronic kidney disease and diabetes mellitus. Assessment of physician awareness based on these indications as well as other indications from JNC 7, such as post-myocardial infarction, stage $\mathrm{C}$ heart failure, and cerebrovascular accident. About $58 \%(n=223)$ of the participants agreed to use ACE inhibitors or ARBs as a first line for the management of hypertension with renal impairment in a patient without renal artery stenosis. For management of hypertension in a patient with $\mathrm{DM}$, about $78.75 \%(\mathrm{n}=304)$ of the physicians agreed to use one of the four medication classes (ACEi/ARB, calcium channel blockers, or diuretics) as a first line for this group. In a patient with stage $\mathrm{C}$ heart failure, about $77.25 \%(n=305)$ of the physicians agreed to use standard regimen that consisted of ACEi/ARB, $\beta$ blockers, diuretics, and spironolactone as a first line. For the management of hypertension in ischemic heart disease, about $75 \%(n=295)$ of the physicians agreed to use $\beta$-blockers with the ACE inhibitor as a first line. For recurrent stroke prevention in a hypertensive patient, approximately $62.75 \%(n=243)$ of physicians agreed to use either ACE inhibitors or diuretics as first line. Moreover, only $46 \%(n=179)$ of the participants agreed to use labetalol as a first line agent in a pregnant women with severe hypertension (Table 4).

\section{$\beta$-Blockers in a Patient Without Compelling Indication}

Using $\beta$-blockers in a patient without compiling indications is not recommended in JNC 8 owing to the increased risk of cardiovascular death. However, in JNC $7 \quad \beta$-blockers were used as a first line. Approximately, 64\% $(n=247)$ of the physicians agreed not to use $\beta$-blockers as a first line in a hypertensive patient without compelling indications (Table 5). However, GPs were associated with lower disagreement rates with this as compared to consultants, specialists, and residents.

Table 3 Correct Answers Regarding Hypertension Classification, Goal, and Drug Combination ( $\mathrm{n}=389$ )

\begin{tabular}{|l|l|l|l|l|l|l|l|l|l|l|l|}
\hline \multirow{2}{*}{ HTN Classifications and Goals } & \multicolumn{2}{|l|}{ Consultant } & \multicolumn{2}{l|}{ Specialist } & \multicolumn{2}{l|}{ Resident } & \multicolumn{2}{l|}{ GPs } & \multirow{2}{*}{ Total } & \multirow{2}{*}{ Chi-Square } & \multirow{2}{*}{ P-value } \\
\cline { 2 - 10 } & Freq. & $\%$ & Freq. & $\%$ & Freq. & $\%$ & Freq. & $\%$ & & \\
\hline Prehypertension & 67 & 91.8 & 109 & 74.7 & 63 & 79.7 & 67 & 73.6 & $78.7 \%$ & 15.355 & $0.018 *$ \\
Stage2 HTN & 63 & 86.3 & 125 & 85.6 & 59 & 74.7 & 60 & 65.9 & $78.9 \%$ & 23.286 & $0.001 *$ \\
Goal of BP in elderly ( $\geq 60$ year) & 54 & 74.0 & 96 & 65.8 & 51 & 64.6 & 48 & 52.7 & $64.0 \%$ & 21.321 \\
Need drug combination in stage 2 HTN & 38 & 52 & 86 & 59 & 51 & 65 & 30 & 33 & $52.25 \%$ & 35.856 \\
\hline
\end{tabular}

Note: *Significant $(\mathrm{P}<0.05)$.

Abbreviations: HTN, hypertension; BP, blood pressure; GPs, general practitioners. 
Table 4 Correct Answers Regarding Hypertensive Patients with Compelling Indications ( $\mathrm{n}=389$ )

\begin{tabular}{|c|c|c|c|c|c|c|c|c|c|c|c|}
\hline \multirow[t]{2}{*}{ Compelling Indications } & \multicolumn{2}{|c|}{ Consultant } & \multicolumn{2}{|c|}{ Specialist } & \multicolumn{2}{|c|}{ Resident } & \multicolumn{2}{|l|}{ GPs } & \multirow[t]{2}{*}{ Total } & \multirow[t]{2}{*}{ Chi-Square } & \multirow[t]{2}{*}{ P-value } \\
\hline & Freq. & $\%$ & Freq. & $\%$ & Freq. & $\%$ & Freq. & $\%$ & & & \\
\hline HF (stage C) & 57 & 78 & 125 & 86 & 61 & 77 & 62 & 68 & $77.25 \%$ & 11.215 & 0.082 \\
\hline CKD & 51 & 70 & 84 & 58 & 45 & 57 & 43 & 47 & $58 \%$ & 16.588 & $0.011 *$ \\
\hline First line during pregnancy & 35 & 48 & 71 & 49 & 36 & 46 & 37 & 41 & $46 \%$ & 7.694 & 0.261 \\
\hline CVA & 55 & 75 & 96 & 66 & 51 & 65 & 41 & 45 & $62.75 \%$ & 26.301 & $0.000^{*}$ \\
\hline DM & 62 & 85 & 112 & 77 & 62 & 78 & 68 & 75 & $78.75 \%$ & 26.705 & $0.000 *$ \\
\hline Post MI & 58 & 79 & 118 & 81 & 57 & 72 & 62 & 68 & $75 \%$ & 8.466 & 0.206 \\
\hline
\end{tabular}

Note: *Significant $(\mathrm{P}<0.05)$.

Abbreviations: HF, heart failure; CKD, chronic kidney disease; CVA, cerebrovascular accident; DM, diabetes mellitus; MI, myocardial infraction; GPs, general practitioners.

Table 5 Correct Answer Regarding ACE and ARBs Combination as Well as $\beta$-Blockers Without Compelling Indications ( $\mathrm{n}=389$ )

\begin{tabular}{|c|c|c|c|c|c|c|c|c|c|c|c|}
\hline \multirow[t]{2}{*}{ Drug Recommendation Question } & \multicolumn{2}{|c|}{ Consultant } & \multicolumn{2}{|c|}{ Specialist } & \multicolumn{2}{|c|}{ Resident } & \multicolumn{2}{|l|}{ GPs } & \multirow[t]{2}{*}{ Total } & \multirow[t]{2}{*}{ Chi-Square } & \multirow[t]{2}{*}{$P$-value } \\
\hline & Freq. & $\%$ & Freq. & $\%$ & Freq. & $\%$ & Freq. & $\%$ & & & \\
\hline$\beta$-blockers without compelling indications & 53 & 73 & 96 & 66 & 57 & 72 & 41 & 45 & $64 \%$ & 24.5 & $0.000^{*}$ \\
\hline $\begin{array}{l}\text { ACEls and ARBs } \\
\text { should not be used as combination }\end{array}$ & 54 & 74 & 100 & 68 & 57 & 72 & 46 & 51 & $66.25 \%$ & 28.0 & $0.000^{*}$ \\
\hline
\end{tabular}

Note: *Significant $(P<0.05)$.

Abbreviations: ACEls, angiotensin converting enzyme inhibitors; ARBs, angiotensin receptor blockers; GPs, general practitioners.

\section{ACEI and ARBs Combination}

About $66.25 \%(n=257)$ of the physicians agreed not to combine ACE inhibitors with ARBs for hypertension management (Table 5). Again, lower rate of correct practice was associated with GPs as compared to consultants, specialists, and residents.

\section{Discussion}

The results of this survey, which included 389 physicians representing different settings in Sana'a, Yemen, are the first evaluating awareness of physicians about the management of hypertension in Yemen. The results of this survey showed that all participating physicians have ever heard about the guidelines of JNC 8 without necessarily reflecting on their practice. The majority of the participants $(96.75 \%, 93.5 \%, 86 \%$, and $69.75 \%)$ recommended weight loss, moderate physical exercise, DASH, and reduction of sodium intake, respectively, as parts of lifestyle modifications for a patient with hypertension. Similar findings were obtained from another study conducted in Saudi Arabia. ${ }^{18}$

Regarding hypertension classification, goal, and drug combinations, the majority $(78.7, \mathrm{n}=306)$ of the participants in this study knew the correct definition of the prehypertension state, and agreed that blood pressure greater than $160 / 100 \mathrm{~mm} \mathrm{Hg}$ is classified as stage-2 hypertension. Moreover, about half of the physicians' responses demonstrated that a patient with stage two hypertension needs antihypertensive drugs combination if the first drug cannot achieve blood pressure target.

The JNC 8 guideline recommended reducing blood pressure to less than $150 / 90 \mathrm{~mm} \mathrm{Hg}$ in elderly patients. ${ }^{6}$ In this study, the majority $(64 \%, n=249)$ of physicians agreed that lowering blood pressure to less than 150/ $90 \mathrm{~mm} \mathrm{Hg}$ is the target of their practice. Compared to this finding, $75 \%$ of internal and family medicine residents in Saudi Arabia correctly reported blood pressure targets in the elderly. ${ }^{19}$ The higher awareness among Saudi physicians regarding this point may be attributed, in part, to their updated knowledge about the current guidelines since they have more continuous education opportunities and the guidelines resources are routinely available in their clinic. It's worthy to mention also that the recommendation of blood pressure treatment goal of less than 150/90 mm Hg in elderly patients is based on expert opinion (grade E), and has remained a point of controversy among experts. In this study, awareness of physicians regarding the definition of prehypertensive stage was higher $(78.7, \mathrm{n}=305)$ than the study that was conducted in Jordan by Al-Azzam and his colleague $(36.55 \%)$. Saudi physicians, on the other hand, exhibited higher awareness regarding combination therapy 
in stage 2 hypertension (69.7\%) compared with the Yemeni physicians $(52.25 \%, \mathrm{n}=205)$.

In hypertension with compelling indications, such as chronic kidney disease, diabetes mellitus, heart failure, ischemic heart disease, and cerebrovascular accident, specific antihypertensive medications classes are recommended in order to ameliorate disease progression and to improve patient's outcome., 90,21 For example, in a hypertensive patient with chronic kidney disease, antihypertensive agents that reduce proteinuria have an advantage; therefore, ACE inhibitors or ARBs have been recommended to be more advantageous in such conditions since they improve kidney-related outcomes. ${ }^{22-26}$ However, in the current study, only $58 \%(n=226)$ of the physicians agreed to use ACE inhibitors or ARBs as the first line therapy for the management of hypertension with renal impairment in cases without renal artery stenosis. Physicians' awareness in this study was higher than that of Jordanian physicians $(40.7 \%)$ and lower than that of Saudi physicians (73.4\%). ${ }^{17,19}$ The discrepancy in the awareness level among physicians from different Middle Eastern countries may be attributed to many reasons, such as the date of releasing the guidelines, the strength of the recommendation, the practicing area, and the specialties of the studied groups.

It is well documented that high blood pressure is the most important risk factor for cerebral vascular accidents, and lowering the blood pressure in a hypertensive patient has been confirmed to reduce the relative risk of stroke by $35 \%$ to $44 \%{ }^{27}$ Other studies have proven that a combination of ACE inhibitor with thiazide diuretics has extended benefit in recurrent stroke reduction beyond the reduction in blood pressure. ${ }^{28,29}$ The finding of this study showed that $62.75 \%(n=244)$ of physicians agreed to use either ACE inhibitors, diuretics or combination of both drugs as first line for recurrent stroke prevention in hypertensive patients. Nevertheless, Al-Azzam and his colleague demonstrated in their study that only $21.4 \%$ of the physicians knew the benefits of this combination and recommended its use for their patients. ${ }^{17}$ Again, the variation in the awareness between studies may be attributed, in part, to the time of the releasing JNC 7 guidelines. In this study, the guidelines have been extensively disseminated and adopted by Yemeni physicians since the JNC 7 report was released in 2003 compared with the Jordanian study, which was conducted two years after the release of the JNC 7 guidelines.
Regarding diabetes patients with hypertension, the majority of the Yemeni physicians (78.75\%, $\mathrm{n}=306)$ agreed to use ACE inhibitors, ARBs, thiazide diuretics or calcium channel blockers as the first line therapy for this group of patients. Compared with this finding, $74.3 \%$ of physicians in Saudi Arabia agreed to use any of the above medications as first line in a hypertensive patient with diabetes, ${ }^{19}$ meaning that the recommendations of JNC 8 guidelines were adopted quickly by Yemeni physicians.

The use of ACE inhibitor, $\beta$-blockers, diuretics, and spironolactone as a standard combination for patients with heart failure in stage $\mathrm{C}$ has advantages such as slowing the progression of heart failure and remodeling, decreased mortality, and improved patient's quality of life. ${ }^{8,30,31}$ In this study, the majority $(77.25 \%, \mathrm{n}=300)$ of Yemeni physicians agreed to use this standard therapy in hypertensive patients with stage $\mathrm{C}$ heart failure. Previous studies showed that $40.1 \%$ of Jordanian physicians and $43 \%$ of Kuwaiti physicians correctly selected ACE inhibitors and ARBs, respectively, as the first line in a hypertensive patient with heart failure. ${ }^{17,32}$

Regarding hypertension complicated by ischemic heart disease, studies have shown that both selective and nonselective Beta-1 blockers reduce mortality and the risk of recurrence of myocardial infarction as well as decreasing cardiac dysfunctions. ${ }^{33,34}$ In this study, the majority (75\%, $n=292$ ) of the physicians agreed to use $\beta$-blockers with ACE inhibitors as a first line therapy in a patient who has myocardial infarction and hypertension. Only, 59.3\% of the Jordanian physicians correctly selected $\beta$-blockers as a first line in a hypertensive patient with ischemic heart disease. $^{17}$

Labetalol is an effective antihypertensive agent that blocks both beta-and alpha-adrenergic receptors. It is recommended as a first line agent in pregnant women with severe hypertension. ${ }^{35}$ Unfortunately, only $46 \%$ $(n=179)$ of the participants in our study agreed to use labetalol as a first line agent in pregnant women with severe hypertension. Several studies revealed that labetalol is a preferred antihypertensive agent in chronic hypertension during pregnancy, especially in severe cases since methyldopa has a mild effect on hypertension with slow onset and nifedipine has many adverse effects. ${ }^{10,36,37}$

$\beta$-blockers, according to JNC 8 , are no longer recommended as first line agents to treat hypertension in patients without compelling indication owing to their association with greater risk of cardiovascular death when compared with amlodipine-based regimen. ${ }^{38}$ In 
this study, the adherence to this recommendation was reported by $64 \%(n=249)$ of the Yemeni physicians. Moreover, it was noticed that the consultants, specialists and residents quickly adopted to the updated guideline compared with GPs. Furthermore, combination therapy of ACE inhibitors and ARBs during the management of hypertension patients should be avoided according to JNC 8. Unfortunately, only $66.25 \%(n=258)$ of the Yemeni physicians agreed not to combine ACE inhibitors with ARBs in a patient with hypertension. A comparable result was obtained from family and internal medicine residents in Saudi Arabia where $67.9 \%$ of them agreed not to use ACE inhibitors and ARBs together. ${ }^{19}$

The finding of this study showed small variations among the responses of consultants, specialists, and residents in different areas of questioning, with slight superiority to consultants in some of the questions. However, GPs demonstrated significantly lower knowledge and awareness regarding guidelines of hypertension management.

This study has some potential limitations; the recruitment of physicians was only from Sana'a city, the capital of Yemen, although other cities may have been considered in order to generalize the awareness level. The selfadministered questionnaire is a simple and low-cost tool of measuring awareness. However, it has inherited social desirability, gender, and recall bias, which could lead to overestimation.

\section{Conclusion}

This study highlights the inadequate knowledge of GPs in Yemen towards high blood pressure management. The findings of this study emphasize the necessity of continuous medical educations for physicians that are specially designed to target GPs and to continually update the curricula of medical students in Yemen.

\section{Ethical Approval and Consent to Participate}

The study protocol was approved by the Ethical Committee of the Medical Research at the University of Science and Technology (MECA No: ECA/UST191). Verbal informed consent from participants was acceptable and approved by the Ethical Committee of the Medical Research at the University of Science and Technology. All participants were informed about the objectives of the study and consented to participate.

\section{Acknowledgments}

The authors want to thank $5^{\text {th }}$ year pharmacy students (Dalia Al- Qadi, Tasbeeh Al-Sunidar, Wafa'a Al-Wasabi, Rua'a Ockba, Areej Al-Hitary, Anwar Qadi, Kwther Sary) at University of Science and Technology, Girl Branch for helping in data collection.

\section{Author Contributions}

All authors contributed to data analysis, drafting and revising the article, gave final approval of version to be published, and agree to be accountable for all aspects of the work.

\section{Disclosure}

The authors declare that there is no conflicts of interest.

\section{References}

1. Kearney PM, Whelton M, Reynolds K, Muntner P, Whelton PK, He J. Global burden of hypertension: analysis of worldwide data. Lancet. 2005;365(9455):217-223. doi:10.1016/S0140-6736(05) 17741-1.

2. Lackland DT, Weber MA. Global burden of cardiovascular disease and stroke: hypertension at the core. Can J Cardiol. 2015;31 (5):569-571. doi:10.1016/j.cjca.2015.01.009.

3. Wang H, Naghavi M, Allen C, et al. Global, regional, and national life expectancy, all-cause mortality, and cause-specific mortality for 249 causes of death, 1980â 2015: a systematic analysis for the Global Burden of Disease Study 2015. Lancet. 2016;388(10053):1459-1544. doi:10.1016/S0140-6736(16)31012-1

4. Singh R, Suh I, Singh V, et al. Hypertension and stroke in Asia: prevalence, control and strategies in developing countries for prevention. J Hum Hypertens. 2000;14(10):749-763. doi:10.1038/sj. jhh.1001057

5. Wong TY, Mitchell P. The eye in hypertension. Lancet. 2007;369 (9559):425-435. doi:10.1016/S0140-6736(07)60198-6.

6. James PA, Oparil S, Carter BL, et al. 2014 evidence-based guideline for the management of high blood pressure in adults: report from the panel members appointed to the Eighth Joint National Committee (JNC 8). JAMA. 2014;311(5):507-520.

7. Chobanian AV. National heart, lung, and blood institute joint national committee on prevention, detection, evaluation, and treatment of high blood pressure; national high blood pressure education program coordinating committee: the seventh report of the joint national committee on prevention, detection, evaluation, and treatment of high blood pressure: the JNC 7 report. JAMA. 2003;289:2560-2572. doi:10.1001/jama.289.19.2560

8. Yancy CW, Jessup M, Bozkurt B, et al. 2013 ACCF/AHA guideline for the management of heart failure: executive summary: a report of the American College of Cardiology Foundation/American Heart Association Task Force on practice guidelines. J Am Coll Cardiol. 2013;62(16):1495-1539. doi:10.1016/j.jacc.2013.05.020

9. Eckel RH, Jakicic JM, Ard JD, et al. 2013 AHA/ACC guideline on lifestyle management to reduce cardiovascular risk: a report of the American College of Cardiology/American Heart Association Task Force on Practice Guidelines. J Am Coll Cardiol. 2014;63(25Part B):2960-2984. doi:10.1016/j.jacc.2013.11.003

10. ACOG. ACOG Practice Bulletin No. 203: chronic hypertension in pregnancy. Obstet Gynecol. 2019;133(1):e26-e50. 
11. Arnett DK, Blumenthal RS, Albert MA, et al. 2019 ACC/AHA guideline on the primary prevention of cardiovascular disease: executive summary: a report of the American College of Cardiology/ American Heart Association task force on clinical practice guidelines. $J$ Am Coll Cardiol. 2019;74(10):1376-1414. doi:10.1016/j.jacc.2019.03.009

12. Hill MN, Miller NH, Degeest S, et al. Adherence and persistence with taking medication to control high blood pressure. J Am Soc Hypertens. 2011;5(1):56-63. doi:10.1016/j.jash.2011.01.001

13. Ardery G, Carter BL, Milchak JL, et al. Explicit and implicit evaluation of physician adherence to hypertension guidelines. $J$ Clin Hypertens (Greenwich). 2007;9(2):113-119. doi:10.1111/j.15246175.2007.06112.x

14. Motlagh B, O’Donnell M, Yusuf S. Prevalence of cardiovascular risk factors in the Middle East: a systematic review. Eur J Cardiovasc Prev Rehabil. 2009;16(3):268-280. doi:10.1097/HJR.0b013e328322ca1b.

15. Al-Shaer MY, Bamashmus MA, Al-Akily SA, Al-Akhlee HA. Prevalence of hypertension, diabetes mellitus and Hepatitis B and $\mathrm{C}$ among people seeking cataract surgery in eye camps in Yemen. Yemeni J Med Health Res. 2019;8:1\&2.

16. MOPHP. Annual Statistical Health Report. mophp website 2014. Available from: http://www.mophp-ye.org/arabic/docs/Report2011. pdf. Accessed March 1, 2019..

17. Al-Azzam SI, Najjar RB, Khader YS. Awareness of physicians in Jordan about the treatment of high blood pressure according to the seventh report of the Joint National Committee (JNC VII). Eur $J$ Cardiovasc Nurs. 2007;6(3):223-232. doi:10.1016/J. EJCNURSE.2006.10.001.

18. Al-Gelban KS, Khan MY, Al-Khaldi YM, et al. Adherence of primary health care physicians to hypertension management guidelines in the Aseer region of Saudi Arabia. Saudi J Kidney Dis Transpl. 2011;22(5):941-948.

19. Alshehri NA, Almigbal TH, Alodhayani A, Batais MA. Family and internal medicine resident's awareness of and adherence to the Joint National Committee 8 (JNC 8) hypertension guidelines: a cross sectional study. Biomed Res. 2017;28:12.

20. Haller H, Ito S, JL I Jr, et al. Olmesartan for the delay or prevention of microalbuminuria in type 2 diabetes. $N$ Engl J Med. 2011;364 (10):907-917. doi:10.1056/NEJMoa1007994

21. Whelton PK, Carey RM, Aronow WS, et al. 2017 ACC/AHA/AAPA/ $\mathrm{ABC} / \mathrm{ACPM} / \mathrm{AGS} / \mathrm{APhA} / \mathrm{ASH} / \mathrm{ASPC} / \mathrm{NMA} / \mathrm{PCNA}$ guideline for the prevention, detection, evaluation, and management of high blood pressure in adults: a report of the American College of Cardiology/ American Heart Association Task Force on Clinical Practice Guidelines. J Am Coll Cardiol. 2018;71(19). e127-e248.

22. Strippoli GF, Craig M, Deeks JJ, Schena FP, Craig JC. Effects of angiotensin converting enzyme inhibitors and angiotensin II receptor antagonists on mortality and renal outcomes in diabetic nephropathy: systematic review. BMJ. 2004;329(7470):828. doi:10.1136/ bmj.38237.585000.7C.

23. Contreras G, Greene T, Agodoa LY, et al. Blood pressure control, drug therapy, and kidney disease. Hypertension. 2005;46(1):44-50. doi:10.1161/01.HYP.0000166746.04472.60

24. Silvariño R, Rios P, Baldovinos G, et al. Is chronic kidney disease progression influenced by the type of renin-angiotensin-system blocker used? Nephron. 2019;143(2):100-107. doi:10.1159/ 000500925
25. Zheng CM, Wang JY, Chen TT, et al. Angiotensin-converting enzyme inhibitors or angiotensin receptor blocker monotherapy retard deterioration of renal function in Taiwanese chronic kidney disease population. Sci Rep. 2019;9(1):2694. doi:10.1038/s41598-01938991-z

26. DeJong C, Grant RW. Continuation of angiotensin-converting enzyme inhibitors and angiotensin receptor blockers in the face of kidney disease progression-safe and possibly life saving. JAMA Intern Med. 2020;180(5):727. doi:10.1001/ jamainternmed.2020.0300.

27. Neal B, MacMahon S, Chapman N;for Blood Pressure Lowering Treatment Trialists' Collaboration. Effects of ACE inhibitors, calcium antagonists, and other blood-pressure-lowering drugs: results of prospectively designed overviews of randomised trials. Blood Pressure Lowering Treatment Trialists' Collaboration. Lancet. 2000;356(9246):1955-1964. doi:10.1016/s0140-6736(00)03307-9.

28. Harrow C, Fisher M. Strokes and diabetes. Pract Diabetes Int. 2005;22(6):215-221. doi:10.1002/pdi.820.

29. Tzourio C, Anderson C, Chapman N, et al. for PROGRESS Collaborative Group. Effects of blood pressure lowering with perindopril and indapamide therapy on dementia and cognitive decline in patients with cerebrovascular disease. Arch Intern Med. 2003;163:1069-1075.

30. Pitt B, Pfeffer MA, Assmann SF, et al. Spironolactone for heart failure with preserved ejection fraction. $N$ Engl J Med. 2014;370 (15):1383-1392. doi:10.1056/NEJMoa1313731

31. Edelmann F, Musial-Bright L, Gelbrich G, et al. Tolerability and feasibility of beta-blocker titration in HFpEF versus HFrEF: insights from the CIBIS-ELD trial. JACC Heart Fail. 2016;4(2):140-149. doi:10.1016/j.jchf.2015.10.008

32. Al-Ali KA, Al-Ghanim FA, Al-Furaih AM, Al-Otaibi N, Makboul G, El-Shazly MK. Awareness of hypertension guidelines among family physicians in primary health care. Alexandria J Med. 2013;49 (1):81-87. doi:10.1016/j.ajme.2012.07.003.

33. Himmelmann A. New information on the role of beta-blockers in cardiac therapy. Cardiovasc Drugs Ther. 1999;13(6):469-477. doi:10.1023/A:1007893301243.

34. Khan NA, McAlister FA, Rabkin SW, et al. The 2006 Canadian Hypertension Education Program recommendations for the management of hypertension: part II - Therapy. Can J Cardiol. 2006;22 (7):583-593. doi:10.1016/S0828-282X(06)70280-X

35. Raio L, Bolla D, Baumann M. Hypertension in pregnancy. Curr Opin Cardiol. 2015;30(4):411-415. doi:10.1097/HCO.0000000000000190.

36. Battarbee AN, Sinkey RG, Harper LM, Oparil S, Tita ATN. Chronic hypertension in pregnancy. Am J Obstet Gynecol. 2020;222 (6):532-541. doi:10.1016/j.ajog.2019.11.1243.

37. Shah S. Hypertensive Disorders in Pregnancy. Obstetric and Gynecologic Nephrology. Springer; 2020:11-23.

38. Dahlöf B, Sever PS, Poulter NR, et al. Prevention of cardiovascular events with an antihypertensive regimen of amlodipine adding perindopril as required versus atenolol adding bendroflumethiazide as required, in the Anglo-Scandinavian Cardiac Outcomes Trial-Blood Pressure Lowering Arm (ASCOT-BPLA): a multicentre randomised controlled trial. Lancet. 2005;366(9489):895-906. doi:10.1016/ S0140-6736(05)67185-1 


\section{Publish your work in this journal}

The International Journal of General Medicine is an international, peer-reviewed open-access journal that focuses on general and internal medicine, pathogenesis, epidemiology, diagnosis, monitoring and treatment protocols. The journal is characterized by the rapid reporting of reviews, original research and clinical studies

across all disease areas. The manuscript management system is completely online and includes a very quick and fair peer-review system, which is all easy to use. Visit http://www.dovepress.com/ testimonials.php to read real quotes from published authors.

Submit your manuscript here: https://www.dovepress.com/international-journal-of-general-medicine-journal 